\title{
Impact of Dietetic Intervention on Metabolic Syndrome Patients Attending Diet Therapy Clinic: A prospective, Single-Arm Intervention Study
}

\author{
Prince Kwabena Osei ${ }^{1,2}$, Collins Appiah ${ }^{2} \&$ Alex Kojo Anderson ${ }^{1}$ \\ ${ }^{1}$ Department of Nutritional Sciences, College of Family and Consumer Sciences, University of Georgia, USA \\ ${ }^{2}$ Department of Biochemistry and Biotechnology, Faculty of Biosciences, College of Science, Kwame Nkrumah \\ University of Science and Technology, Kumasi, Ghana \\ Correspondence: Prince Kwabena Osei, Department of Nutritional Sciences, University of Georgia, USA. Tel: \\ 233-246-797-891.
}

Received: April 23, 2021 Accepted: June 2, 2021 Online Published: June 14, 2021

doi:10.5539/gjhs.v13n7p89

URL: https://doi.org/10.5539/gjhs.v13n7p89

\begin{abstract}
Introduction: The prevalence of metabolic syndrome (MetS) is rising globally. Dietetic intervention, as part of a multidisciplinary team approach, is increasingly being recommended for the effective management of patients with MetS. This study was designed to assess the impact of a dietetic intervention on MetS characteristics of patients attending the Diet Therapy Clinic at Tema General Hospital, Ghana.
\end{abstract}

Methodology: A prospective pre-post single-arm intervention study was conducted among 168 participants who had been diagnosed with MetS and were referred to the Diet Therapy Clinic for dietetic intervention. Data on body mass index (BMI), waist circumference (WC), fasting blood glucose (FBG), high-density lipoprotein (HDL), serum triglyceride (TG), and blood pressure (BP) were collected at baseline and after three months of receiving a dietetic intervention.

Results: The MetS measures (BMI, WC, FBG, HDL and TG) of the patients improved at the end of the three months period $\left(32.9 \mathrm{~kg} / \mathrm{m}^{2}\right.$ vs $31.7 \mathrm{~kg} / \mathrm{m}^{2}, \mathrm{p}=0.001 ; 101.2 \mathrm{~cm}$ vs $98.9 \mathrm{~cm}, \mathrm{p}=0.001 ; 11.0 \mathrm{mmol} / \mathrm{L} \mathrm{vs} 7.7 \mathrm{mmol} / \mathrm{L}$, $\mathrm{p}=0.001 ; 1.1 \mathrm{mmol} / \mathrm{L}$ vs $1.2 \mathrm{mmol} / \mathrm{L}, \mathrm{p}=0.001 ; 2.0 \mathrm{mmol} / \mathrm{L}$ vs $1.9 \mathrm{mmol} / \mathrm{L}, \mathrm{p}=0.001$ respectively). There were improvements in the mean systolic and diastolic BP values recorded after the three months $(153 \mathrm{mmHg}$ vs 131 $\mathrm{mmHg}, \mathrm{p}=0.001$ and $98 \mathrm{mmHg}$ vs $85 \mathrm{mmHg}, \mathrm{p}=0.001$ respectively).

Conclusion: Dietetic intervention was found to have improved the MetS characteristics of patients.

Keywords: dietetic intervention, diet therapy, metabolic syndrome

\section{Introduction}

Metabolic syndrome (MetS) is a cluster of biochemical and physiological disorders which is characterized by component risk factors comprising dyslipidemia, hypertension, insulin resistance, and abdominal obesity (Alberti et al., 2009). The pathophysiology of MetS has not been completely understood (Moore, Chaudhary, \& Akinyemiju, 2017). Abdominal obesity seems to trigger a sequence of metabolic changes that eventually lead to the development of MetS (Huang, 2009). Some of these metabolic changes include insulin resistance, elevated blood lipid profile, and high blood pressure (Alberti et al., 2009). Therefore, people who are obese are highly likely to develop the syndrome, and a study by Dixon et al. (2011) on an adult population, found that $5 \%$ of the study population who had normal body weight had MetS. However, $22 \%$ of those who were overweight, as well as $60 \%$ of those categorized as obese, had MetS.

Persistent intakes of atherogenic diets which are mostly high in calories and inadequate physical activity have been identified as major contributory factors to developing MetS (Moore, Chaudhary, \& Akinyemiju, 2017). Also, the risk of MetS increases with age, and family history of the syndrome can be a risk factor (Huang, 2009). However, lifestyle changes comprising increased physical activity and dietary modifications have been shown in many studies to be effective treatment approaches for MetS (Doyle et al., 2012)

The prevalence of MetS is different in many countries across the globe and an estimated $25 \%$ of the world's adult population has MetS (Moore, Chaudhary, \& Akinyemiju, 2017). Many countries have seen a surge in the 
prevalence of MetS since the twentieth century (WHO, 2008). In the US, analysis of existing data on MetS from the National Health and Nutrition Examination Survey between the years 1988 to 2012, observed significant rises in MetS prevalence among the adult population (Moore, Chaudhary, \& Akinyemiju, 2017). In Asia, the prevalence of MetS is estimated to be between 12 and 37\% whereas, in Europe prevalence is estimated to range from 12 to $26 \%$ (Ranasinghe et al., 2011). In Africa, the prevalence of MetS ranges from 0 to $50 \%$ and some studies have also been done in specific countries regarding the prevalence of MetS (Okafor, 2012).

In Nigeria, a study by Akintunde et al. (2012) found the prevalence of MetS in their study to be $28.1 \%$. A study by Garrido et al. (2009), in Botswana, also found the prevalence of MetS to be $34 \%$. A similar study by Tran et al. (2011), in Ethiopia, reported a prevalence of $17.9 \%$. In Ghana, MetS continue to be a major public health challenge, and a systematic review of existing data from 2005 to 2011 by Ofori-Asenso et al. (2017), using the NCEP ATP III criteria found the mean prevalence of MetS to be $12.4 \%$.

Even though lifestyle changes comprising increased physical activity and dietary modifications have been shown in many studies to be an effective therapy for MetS (Doyle et al., 2012), some patients find it difficult to follow dietary counseling interventions. There are underlining factors that influence the compliance of patients to dietetic intervention (Mensah \& Asamoah, 2016). A study by Nancy et al. (2013) identified poverty, lack of family support, lack of time, and communication barriers as factors that influenced compliance to dietetic intervention. Another study in Ghana by Mensah and Asamoah (2016), at the diabetic clinic of Komfo Anokye Teaching Hospital, identified perceived wrong beliefs, medication cost, level of education, and injury prevention as the main factors that influenced compliance of patients to medical nutrition therapy.

Currently, there is limited data in the literature, in Ghana, about the impact of dietetic intervention on the MetS characteristics of patients. Also, there is a dearth of documented information on the impact of dietetic intervention offered by dietitians through medical nutrition therapy on MetS characteristics in Ghana. Hence, there was the need to carry out this study to determine the impact of the dietetic intervention on the MetS characteristics of patients and to also assess the level of compliance of MetS patients to the dietetic intervention.

\section{Materials and Methods}

\subsection{Study Design, Study Site, and Period}

A prospective pre-post single-arm intervention study design was used for this study. The study was carried out at the Diet Therapy Clinic at a General Hospital in Tema metropolis, Ghana. The study was conducted between October 2018 and March 2019.

\subsection{Study Population}

The study population at the start of the research comprised 180 patients who had been newly diagnosed with MetS and were attending the Diet Therapy Clinic of a General Hospital in Tema, Ghana for dietetic intervention.

\subsection{Sampling and Recruitment of Participants}

Purposive sampling was used in selecting patients for the study. Out-patients who had been newly diagnosed with MetS and were referred by physicians to see dietitians at the Diet Therapy Clinic for dietetic intervention were invited to participate in the study. Details of the study were explicitly explained to the patients before recruitment into the study. The results of their biochemical laboratory analysis (FBG, TG, and HDL) were taken from physicians and recorded as part of their baseline data. In addition, the blood pressure (BP) and anthropometric measures (weight, height, body mass index (BMI), and waist circumference) of the patients were measured at the diet therapy clinic, and results were also recorded accordingly as baseline data. Patients were recruited into the study if they met any three of the National Cholesterol Education Program (NCEP ATP III 2005) criteria for diagnosing MetS. Each patient who agreed to participate in the study signed a consent form before being enrolled in the study. The patients were also informed that if for any reason they want to discontinue participation in the research, they were free to do so by informing the researcher. A total of 180 patients were recruited into the study.

\subsection{Description of the Dietetic Intervention}

Participants were offered face-to-face individualized dietary counseling by the resident dietitians per the standard protocols at the Diet Therapy Clinic. The researcher did not influence the intervention offered by the resident dietitians. Each participant was counseled on lifestyle modifications such as dietary modification based on individualized calorie and nutrient requirements to control weight, blood glucose, lipid, and blood pressure levels. Food models of Ghanaian foods were used to explain recommended serving sizes of food based on the estimated individual calorie and macronutrient requirements. Diets rich in fruits, vegetables, legumes, whole grains as well as fish, nuts, low sodium, and low-fat dairy products among others, were integral components of the dietary 
counseling recommendations that were offered to the participants. In addition, participants were counseled to adopt a more physically active lifestyle to avoid excessive weight gain. The dietitians spent an average of 30-45 minutes on each participant per session. Each participant was re-assessed three months after their first consultation with the dietitians.

\subsection{Baseline Data}

In addition to the anthropometric measures (weight, height, BMI, and WC), BP, FBG, TG, and HDL readings, which were taken from participants as baseline data, information regarding the socio-demographic characteristics of the participants were also collected with a semi-structured questionnaire.

\subsubsection{Anthropometric Data Collection}

A Seca measuring tape (max. length $-205 \mathrm{~cm}$ ) was used to measure the $\mathrm{WC}$ of participants. Readings were measured to the nearest $0.1 \mathrm{~cm}$. WC was measured at the mid-point of the lower border of the rib cage and the iliac crest.

An Omron weighing scale (max. capacity $-150 \mathrm{~kg}$ ) was used to measure the weight of participants. Before each weighing was done, participants were asked to remove any heavy objects and clothes from themselves to get accurate readings.

A Seca stadiometer (max. length $-205 \mathrm{~cm}$ ) was also used to measure the heights of all participants. Participants were asked to remove their footwear and stand upright on the stadiometer before readings were taken.

The weight and height measures were used to calculate the BMI. All readings were measured to the nearest $0.1 \mathrm{~kg}$ and $0.1 \mathrm{~cm}$ for both weight and height respectively. For each anthropometric measure, readings were done in duplicates and if any two readings were found to be out of tolerance (Weight $\pm 0.1 \mathrm{~kg}$, Height $\pm 0.1 \mathrm{~cm}, \mathrm{WC} \pm 0.1$ $\mathrm{cm}$ ), a third reading was taken for that anthropometric measure. Any two of the three readings which were found to be within tolerance were averaged.

\subsubsection{Biochemical Data Collection}

Biochemical assessments of FBG, TG, and HDL were done on the blood samples of all participants. Approximately $5 \mathrm{~mL}$ of blood samples were taken by a laboratory phlebotomist from each participant for the aforementioned laboratory analyses.

\subsubsection{Blood Pressure Data Collection}

A mercury sphygmomanometer was used by dietitians to measure both the systolic and diastolic blood pressure of participants. Each participant was measured in a sitting position after they have had at least 15 minutes of rest. Readings were done in duplicates. If the two readings taken were found to be out of tolerance $( \pm 1 \mathrm{mmHg})$, a third measurement was taken. Any two of the three readings taken which were found to be within tolerance were averaged.

\subsection{Endpoint Data}

After three months of dietetic intervention with monthly follow-up review visits, 12 participants dropped out and the 168 , who could follow the research protocols were re-assessed by taking repetitive measurements of their baseline measures. The participants were taken through an interview to assess their attitudes towards dietetic intervention and their levels of compliance. Lastly, data on the main factors which influenced the compliance of participants to the dietetic intervention were also collected.

\subsection{Ethical Considerations}

Ethical approval with reference number CHRPE/AP/636/18 was given by the Committee on Human Research, Publications and Ethics (CHRPE) of the School of Medical Sciences, Kwame Nkrumah University of Science and Technology (KNUST). In addition, approval was granted by the management of the Tema General Hospital for the study to be carried out, and informed consent was also sought from each participant. All participants were notified before the study that participation was voluntary before signing the informed consent form.

\subsection{Statistical Analysis}

Data from this study were analyzed with Statistical Package for Social Sciences (SPSS) version 16. An independent sample t-test was used to compare the mean variables of males and females. Paired sample t-test was used to compare the means outcome variables between baseline and endpoint. Fisher's exact test was used to test the relationships between socio-demographic characteristics and level of compliance of participants to dietetic intervention. Statistical significance was set at $\mathrm{p}<0.05$. 


\section{Results}

Data on socio-demographic characteristics of the study participants are shown in Table 1 . The majority (76.2\%) of the study participants were females. About $23.2 \%$ of the participants had no formal education, although $23.8 \%$ had tertiary education. Approximately $7.1 \%$ of the participants were unemployed and $41.7 \%$ were engaged in petty trading. About $12.5 \%$ were pensioners and $6.0 \%$ reported monthly incomes below 500 Ghana cedis (100 US dollars). Anthropometric, biochemical, and blood pressure measures of participants by gender at baseline are presented in Table 2. The mean BMI for males was found to be significantly lower than that for females. The mean WC for males was found to be slightly lower than that for females. Fasting blood glucose, HDL cholesterol, and triglycerides levels did not differ significantly between males and females. The systolic and diastolic BP readings recorded at baseline indicated that males had comparatively higher averages than females.

Table 3 shows the anthropometric, biochemical, and blood pressure measures recorded at the endpoint for both males and females. The mean BMI of females $\left(32.5 \pm 5.2 \mathrm{~kg} / \mathrm{m}^{2}\right)$ was significantly $(\mathrm{p}=0.004)$ higher than that of males $\left(29.2 \pm 2.8 \mathrm{~kg} / \mathrm{m}^{2}\right)$. Female participants also had significantly higher mean WC than males $(99.1 \pm 7.6 \mathrm{vs}$ $98.2 \pm 4, p=0.018)$. The endpoint biochemical measures of participants did not differ significantly between males and females ( $p$ values $>0.05$ ). The average BP levels of participants reduced at the endpoint for both males and females. From Table 4, the MetS measures of both males and females before and after the intervention were found to be statistically significant. Shown in Table 5 are the MetS measures of the participants before and after the intervention. The differences in all anthropometric, biochemical, and blood pressure data measured for the various variables at baseline and endpoint were statistically significant.

The majority of the study participants reported that their compliance was good. The main factors reported by the participants to have influenced their compliance were grouped under food restrictions, taking specific food servings, and engaging in aerobic exercises. Many of the participants (44.6\%) responded under all three groupings that their desire to recover from MetS was the main factor that influenced their compliance with the dietetic intervention (Table 6).

Table 1. Socio-demographic Characteristics of Participants

\begin{tabular}{lcc}
\hline Variable & Frequency (n) & Percentage (\%) \\
\hline Gender & 40 & 23.8 \\
Male & 128 & 76.2 \\
Female & & \\
\hline Age (years) & 8 & 4.8 \\
$18-35$ & 35 & 20.8 \\
$36-45$ & 67 & 39.9 \\
$46-60$ & 58 & 34.5 \\
$>60$ & 39 & 23.2 \\
\hline & 52 & 31.0 \\
Level of Education & 37 & 22.0 \\
Never & 40 & 23.8 \\
JHS & & \\
SHS & & \\
Tertiary & 141 & 83.9 \\
\hline Religious Affiliation & 18 & 10.7 \\
Christian & 5 & 3.0 \\
Muslim & 4 & 2.4 \\
Buddhist & & \\
Traditionalist & & \\
\hline
\end{tabular}




\section{Marital Status}

\begin{tabular}{lcc} 
Single & 20 & 11.9 \\
Married & 104 & 61.9 \\
Divorced & 17 & 10.1 \\
Widowed & 27 & 16.1 \\
\hline Occupation & & 19.0 \\
Civil servant & 32 & 41.7 \\
Trader & 70 & 3.0 \\
Farmer & 5 & 12.5 \\
Artisans & 21 & 12.5 \\
Retired/Pensioner & 21 & 4.2 \\
Food chef & 7 & 7.1 \\
Unemployed & 12 & 19.0 \\
\hline Monthly Income & & 42.3 \\
$<500$ cedis (100 USD) & 10 & 32.7 \\
$500-1000$ (200USD) & 32 & 6.0 \\
$100-2000$ (400USD) & 71 & 5 \\
$>2000$ (400USD) & 55 & \\
\hline
\end{tabular}

Table 2. anthropometric, biochemical and blood pressure measures of participants by gender at baseline

\begin{tabular}{|c|c|c|c|c|}
\hline \multirow{2}{*}{ Variables } & \multicolumn{3}{|c|}{ Mean \pm SD } & \multirow{2}{*}{ P-value } \\
\hline & Males $(n=40)$ & Female $(n=128)$ & Total $(n=168)$ & \\
\hline Weight (kg) & $85.6 \pm 8.1$ & $83.2 \pm 14.4$ & $83.7 \pm 13.2$ & 0.002 \\
\hline Height (m) & $1.7 \pm 0.1$ & $1.6 \pm 0.1$ & $1.6 \pm 0.1$ & 0.404 \\
\hline $\operatorname{BMI}\left(\mathrm{kg} / \mathrm{m}^{2}\right)$ & $30.5 \pm 2.4$ & $33.6 \pm 4.9$ & $32.9 \pm 4.6$ & 0.006 \\
\hline $\mathrm{WC}(\mathrm{cm})$ & $101.2 \pm 3.8$ & $101.3 \pm 7.0$ & $101.2 \pm 6.3$ & 0.005 \\
\hline $\mathrm{FBG}(\mathrm{mmol} / \mathrm{l})$ & $10.9 \pm 3.5$ & $11.0 \pm 3.1$ & $11.0 \pm 3.2$ & 0.339 \\
\hline HDL (mmol/l) & $1.0 \pm 0.2$ & $1.1 \pm 0.2$ & $1.1 \pm 0.2$ & 0.215 \\
\hline Systolic BP (mmHg) & $155 \pm 12$ & $153 \pm 11$ & $153 \pm 12$ & 0.646 \\
\hline Serum TG (mmol/l) & $2.1 \pm 0.2$ & $2.0 \pm 0.3$ & $2.0 \pm 0.3$ & 0.336 \\
\hline Diastolic BP (mmHg) & $99 \pm 7$ & $97 \pm 6$ & $98 \pm 6$ & 0.998 \\
\hline
\end{tabular}

Data represented as (mean $\pm \mathrm{SD}$ ) where $\mathrm{SD}=$ standard deviation, $\mathrm{n}=$ frequency, $\mathrm{BMI}=$ Body Mass Index, and $\mathrm{WC}=$ waist circumference. $\mathrm{FBG}=$ Fasting Blood Glucose, $\mathrm{HDL}=$ High Density Lipoprotein, $\mathrm{TG}=$ Triglyceride. $\mathrm{BP}=\mathrm{Blood}$ Pressure. $\mathrm{Mean}$ values are statistically significant at $\mathrm{p}<0.05$. 
Table 3. Anthropometric, Biochemical and Blood Pressure Measures of Participants by Gender at Endpoint

\begin{tabular}{|c|c|c|c|c|}
\hline \multirow[t]{2}{*}{ Variables } & \multicolumn{3}{|l|}{ Mean \pm SD } & \multirow[t]{2}{*}{ P-value } \\
\hline & Males $(n=40)$ & Female $(n=128)$ & Total $(n=168)$ & \\
\hline Weight (kg) & $82.0 \pm 8.4$ & $80.6 \pm 15.2$ & $80.9 \pm 13.8$ & 0.002 \\
\hline Height (m) & $1.7 \pm 0.1$ & $1.6 \pm 0.1$ & $1.6 \pm 0.1$ & 0.404 \\
\hline BMI $\left(\mathrm{kg} / \mathrm{m}^{2}\right)$ & $29.2 \pm 2.8$ & $32.5 \pm 5.2$ & $31.7 \pm 5.0$ & 0.004 \\
\hline $\mathrm{WC}(\mathrm{cm})$ & $98.2 \pm 4.2$ & $99.1 \pm 7.6$ & $98.9 \pm 7.0$ & 0.018 \\
\hline FBG (mmol/l) & $7.6 \pm 2.6$ & $7.8 \pm 2.8$ & $7.7 \pm 2.8$ & 0.867 \\
\hline $\operatorname{HDL}(\mathrm{mmol} / \mathrm{l})$ & $1.1 \pm 0.3$ & $1.2 \pm 0.2$ & $1.2 \pm 0.3$ & 0.384 \\
\hline Serum TG (mmol/l) & $1.9 \pm 0.3$ & $1.9 \pm 0.4$ & $1.9 \pm 0.3$ & 0.208 \\
\hline Systolic BP (mmHg) & $131 \pm 11$ & $131 \pm 11$ & $131 \pm 11$ & 0.566 \\
\hline Diastolic BP (mmHg) & $86 \pm 7$ & $85 \pm 6$ & $85 \pm 7$ & 0.072 \\
\hline
\end{tabular}

Data represented as (mean $\pm \mathrm{SD}$ ) where $\mathrm{SD}=$ standard deviation, $\mathrm{n}=$ frequency, $\mathrm{BMI}=$ Body Mass Index, and $\mathrm{WC}=$ waist circumference. $\mathrm{FBG}=$ Fasting Blood Glucose, $\mathrm{HDL}=$ High Density Lipoprotein, $\mathrm{TG}=$ Triglyceride. $\mathrm{BP}=\mathrm{Blood}$ Pressure .

Table 4. Metabolic syndrome measures of males and females before and after intervention

\begin{tabular}{|c|c|c|c|c|c|c|c|c|}
\hline \multirow[t]{2}{*}{ Variables } & \multicolumn{4}{|c|}{ Males } & \multicolumn{4}{|c|}{ Females } \\
\hline & $\begin{array}{l}\text { Baseline } \\
\text { Mean } \pm \text { SD }\end{array}$ & $\begin{array}{l}\text { End Point } \\
\text { Mean } \pm \text { SD }\end{array}$ & $\begin{array}{l}\text { Mean } \\
\text { change }\end{array}$ & p-value & $\begin{array}{l}\text { Baseline } \\
\text { Mean } \pm \text { SD }\end{array}$ & $\begin{array}{l}\text { End Point } \\
\text { Mean } \pm \text { SD }\end{array}$ & $\begin{array}{l}\text { Mean } \\
\text { change }\end{array}$ & p-value \\
\hline Weight (kg) & $85.6 \pm 8.1$ & $82.0 \pm 8.4$ & -3.6 & 0.001 & $83.2 \pm 14.4$ & $80.6 \pm 15.2$ & -2.6 & 0.001 \\
\hline BMI $\left(\mathrm{kg} / \mathrm{m}^{2}\right)$ & $30.5 \pm 2.4$ & $29.2 \pm 2.8$ & -1.3 & 0.001 & $33.6 \pm 4.9$ & $32.5 \pm 5.2$ & -1.1 & 0.001 \\
\hline $\mathrm{WC}(\mathrm{cm})$ & $101.2 \pm 3.8$ & $98.2 \pm 4.2$ & -3.0 & 0.001 & $101.3 \pm 7.0$ & $99.1 \pm 7.6$ & -2.2 & 0.001 \\
\hline $\mathrm{FBG}(\mathrm{mmol} / \mathrm{l})$ & $10.9 \pm 3.5$ & $7.6 \pm 2.6$ & -3.3 & 0.001 & $11.0 \pm 3.1$ & $7.8 \pm 2.8$ & -3.2 & 0.001 \\
\hline HDL (mmol/l) & $1.0 \pm 0.2$ & $1.1 \pm 0.3$ & +0.1 & 0.001 & $1.1 \pm 0.2$ & $1.2 \pm 0.2$ & +0.1 & 0.001 \\
\hline Serum TG (mmol/l) & $2.1 \pm 0.2$ & $1.9 \pm 0.3$ & -0.2 & 0.001 & $2.0 \pm 0.3$ & $1.9 \pm 0.4$ & -0.1 & 0.001 \\
\hline Systolic BP (mmHg) & $155 \pm 12$ & $131 \pm 11$ & -24 & 0.001 & $153 \pm 11$ & $131 \pm 11$ & -22 & 0.001 \\
\hline Diastolic BP (mmHg) & $99 \pm 7$ & $86 \pm 7$ & -13 & 0.001 & $97 \pm 6$ & $85 \pm 6$ & -12 & 0.001 \\
\hline
\end{tabular}

Data represented as (mean $\pm \mathrm{SD}$ ) where $\mathrm{SD}=$ standard deviation, $\mathrm{n}=$ frequency, $\mathrm{BMI}=$ Body Mass Index, and $\mathrm{WC}=\mathrm{waist}$ circumference. $\mathrm{FBG}=$ Fasting Blood Glucose, $\mathrm{HDL}=$ High Density Lipoprotein, $\mathrm{TG}=$ Triglyceride. $\mathrm{BP}=\mathrm{Blood}$ Pressure.

Table 5. Metabolic syndrome measures of participants before and after intervention

\begin{tabular}{|c|c|c|c|c|}
\hline Variables & $\begin{array}{l}\text { Baseline } \\
\text { Mean } \pm \text { SD }\end{array}$ & $\begin{array}{l}\text { End Point } \\
\text { Mean } \pm \text { SD }\end{array}$ & Mean change & p-value \\
\hline Weight (kg) & $83.7 \pm 13.2$ & $80.9 \pm 13.8$ & -2.8 & 0.001 \\
\hline BMI $\left(\mathrm{kg} / \mathrm{m}^{2}\right)$ & $32.8 \pm 4.6$ & $31.7 \pm 4.9$ & -1.1 & 0.001 \\
\hline $\mathrm{WC}(\mathrm{cm})$ & $101.2 \pm 6.3$ & $98.9 \pm 7.0$ & -2.3 & 0.001 \\
\hline $\mathrm{FBG}(\mathrm{mmol} / \mathrm{L})$ & $11.0 \pm 3.2$ & $7.7 \pm 2.8$ & -3.2 & 0.001 \\
\hline HDL (mmol/L) & $1.1 \pm 0.2$ & $1.2 \pm 0.3$ & +0.1 & 0.001 \\
\hline Serum TG $(\mathrm{mmol} / \mathrm{L})$ & $2.0 \pm 0.3$ & $1.9 \pm 0.3$ & -0.1 & 0.001 \\
\hline Systolic BP (mmHg) & $153 \pm 12$ & $131 \pm 11$ & -22 & 0.001 \\
\hline Diastolic BP (mmHg) & $98 \pm 6$ & $85 \pm 7$ & -12 & 0.001 \\
\hline
\end{tabular}

Data represented as mean $\pm \mathrm{SD}$. Mean values are statistically significant at $\mathrm{p}<0.05 . \mathrm{SD}=$ standard deviation, $\mathrm{BMI}=$ body mass index, $\mathrm{WC}=$ =waist circumference, $\mathrm{FBG}=$ fasting blood glucose, $\mathrm{TG}=$ triglycerides, $\mathrm{BP}=$ blood pressure. The paired $\mathrm{t}$-test was used to compare means. Mean change was computed from the difference between the means of endpoint and baseline data. Mean values are statistically significant at $\mathrm{p}<0.05$. 
Table 6. Factors reported by participants to have influenced compliance

\begin{tabular}{lcc}
\hline Factors & Frequency (n) & Percentage (\%) \\
\hline Food Restrictions & 83 & 49.4 \\
Desire to recover from MetS & 33 & 19.6 \\
Forgetfulness & 31 & 18.4 \\
Cannot control appetite & 7 & 4.2 \\
Believe MetS is Incurable & 5 & 3.0 \\
Doubt diet Therapy can treat MetS & 9 & 5.4 \\
Lack of proper understanding of what to do & & \\
\hline Taking Specific Food Servings & 84 & 50.0 \\
Desire to recover from MetS & 31 & 18.5 \\
Forgetfulness & 32 & 19.0 \\
Cannot get those foods to buy & 21 & 12.5 \\
Those foods are expensive & & 34.5 \\
\hline Engaging in Aerobic Exercise & 58 & 33.3 \\
Desire to recover from MetS & 56 & 12.5 \\
Busy work schedule/lack of time & 21 & 19.6 \\
No one to support me & 33 & \\
Forgetfulness to exercise & &
\end{tabular}

\section{Discussion}

This study sought to investigate the impact of a dietetic intervention on the MetS characteristics of patients and, to also identify the main factors that influenced the compliance of participants. The results of this study showed improved HDL, TG, FBG, WC, BMI, and, BP levels after three months of following dietetic interventions given by dietitians. The mean systolic and diastolic BP readings recorded at baseline were $153 \mathrm{mmHg}$ and $98 \mathrm{mmHg}$ respectively. These values were found to be higher than the values indicated in the NCEP ATP III criteria (Huang, 2009). As indicated by Thaman and Arora (2013), MetS patients are mostly hypertensive and their BP may be higher than normal. The significant decline in the BMI, WC, TG, systolic and diastolic BP values from baseline to endpoint could be attributed to the dietetic intervention provided by the dietitians during the intervention period.

Previous studies suggest that people with MetS may benefit from intensive lifestyle modifications such as dietary changes and adopting a physically active lifestyle (Nancy et al., 2013). Particularly, eating diets that are rich in fruits, vegetables, legumes, whole grains, fish, nuts, and low-fat dairy products (Yamaoka \& Tango, 2012). These healthy foods, which have protective health effects, were integral components of the dietary recommendations which were offered to the participants.

Findings from the study also revealed that the majority of the participants had a family history of MetS. As stated by Yamaoka and Tango (2012), hereditary is one of the main contributory factors of MetS and the syndrome could run through families. This is factual and in agreement with the observation made. Furthermore, most of the participants who perceived that MetS can run through families were also found to have reported tertiary education as their education level. A study by Bener et al. (2009), also identified a high level of education to be highly associated with reduced incidence of MetS. This previous finding agrees with the observation made from this research.

Regarding participants' perception of the severity of MetS, approximately $74.4 \%$ of the participants perceived that MetS is a serious health condition. As discussed by Glanz and Bishop (2010), beliefs and perceptions are what drive people to change behavior. Because of this, participants who perceived that MetS is not serious were unlikely to follow the dietetic interventions the dietitians recommended for them. According to Kodama et al. (2013), weight loss is particularly effective at reducing insulin resistance, hypertension, and dyslipidemia and, there is evidence that following good dietetic intervention can help deal with MetS.

In this study, the majority of the participants believed that compliance with dietetic intervention can help improve 
their health condition. This could be the reason for the high compliance to the interventions given which is evidenced by the improved HDL, TG, FBG, BP, WC and, BMI levels recorded at the end of the study. The majority of the participants reported that their desire to recover from MetS was their main motivation for adhering to the dietetic interventions. Some reported forgetfulness, a busy work schedule, and lack of control over appetite, as some reasons why they could not fully follow the dietetic interventions. Others also reported that the recommended foods by consulting dietitians were either inaccessible or too expensive. These findings are consistent with a study by Mensah and Asamoah (2016).

Stakeholders who are involved in the prevention and management of MetS should prioritize diet therapy because it could serve as a cost-effective and lifestyle-compatible approach in managing MetS. Further studies, particularly, randomized controlled trials are needed to better establish the efficacy of the dietetic intervention.

\section{Limitations}

The sample size estimated for the study was reduced because some patients dropped out of the study. The authors acknowledge this as a limitation and recommend a larger sample size for a similar study to generalize the findings of the research.

\section{Conclusion}

The dietetic intervention was found to have improved the MetS characteristics of patients. Most participants perceived that MetS is a serious health condition. The majority of the participants reported good compliance with the dietetic intervention. The main factors reported by participants to have influenced compliance were: the desire to recover from MetS, forgetfulness, unavailability of recommended foods, high cost of healthy foods, and busy work schedule.

\section{Author Contribution}

PKO and CA were involved in study design, literature search, data analysis, and AKA was involved in the supervision of write-up.

\section{Statement of Funding}

The research was funded by Olam Ghana Limited. The Tema General Hospital also provided support in terms of making their facility available for the study and, providing all the necessary equipment and materials for the study.

\section{Acknowledgments}

Our foremost heartfelt gratitude goes to the Lord God Almighty for His love, strength, and grace that sustained us to make this study a success. The authors acknowledge the management of Olam Ghana Limited, and the Tema General Hospital for their support and for making their facility available for this research. We acknowledge the entire Diet Therapy Unit staff at the Tema General Hospital for the assistance they gave during data collection at their clinic. We are grateful to all patients who participated in the study. God bless you all.

\section{Competing Interests Statement}

The authors declare that there is no conflict of interest regarding the publication of this research article.

\section{References}

Aguilar, M., Bhuket, T., Liu, B., Torres, S., \& Wong, R. J. (2015). Prevalence of the Metabolic Syndrome in the United States, Journal of the American Medical Association, 313(19). https://doi.org/10.1001/jama.2015.4260

Akintunde, A. A., Ayodele, O. E., Akinwusi, P. O., \& Opadijo, G. O. (2011). Metabolic syndrome: Comparison of Occurrence Using Three Definitions in Hypertensive Patients. Clin Med Res, 9, 26-31. https://doi.10.3121/cmr.2010.902

Akpalu, J., Akpalu, A., \& Ofei, F. (2011). The Metabolic Syndrome among patients with cardiovascular disease in Accra. Ghana Medical Journal. Retrieved from https://www.ncbi.nlm.nih.gov/pmc/articles/PMC3283092

Alberti, K. G. M. M., Eckel, R. H., Grundy, S. M., Zimmet, P. Z., Cleeman, J. I., Donato, K. A., ... \& Smith Jr, S. C. (2009). Harmonizing the metabolic syndrome: a joint interim statement of the international diabetes federation task force on epidemiology and prevention; national heart, lung, and blood institute; American heart association; world heart federation; international atherosclerosis society; and international association for the study of obesity. Circulation, 120(16), 1640-1645. https://doi.org/10.1161/CIRCULATIONAHA.109.192644

Bener, A., Zirie, M., Musallam, M., Khader, Y. S., \& Al-Hamaq, A. O. (2009). Prevalence of metabolic syndrome 
according to Adult Treatment Panel III and International Diabetes Federation criteria: a population-based study. Metabolic syndrome and related disorders, 7(3), 221-230. https://doi.org/10.1089/met.2008.0077

Champion, V. L., \& Skinner C. S. (2008). The health belief model. In K., Glanz, B. K., Rimer, \& K., Viswanath, (Eds.), health behavior and health education: Theory, Research, and Practice (p. 45-65).

Deshpande, S., Basil, M. D., \& Basil, D. Z. (2009). Factors influencing healthy eating habits among college students: An application of the health belief model. Health marketing quarterly, 26(2), 145-164. https://doi.org/10.1080/07359680802619834

Dixon, J. B., Zimmet, P., Alberti, K. G., \& Rubino, F. (2011). Bariatric surgery: an IDF statement for obese Type 2 diabetes. Diabetic medicine: A Journal of the British Diabetic Association, 28(6). https://doi.org/10.1111/j.1464-5491.2011.03306.x

Doyle, S. L., Donohoe, C. L., Lysaght, J., \& Reynolds, J. V. (2012). Visceral obesity, metabolic syndrome, insulin resistance and cancer. Proceedings of the Nutrition Society, 71(1), 181-189. https://doi.org/10.1017/S002966511100320X

Garrido, R. A., Semeraro, M. B., Simi, M. R., \& Temesgen, S. M. (2009). Metabolic Syndrome and Obesity among workers at Kanye Seventh-day Adventist Hospital, Botswana. South Africa Medical Journal, 99(5). Retrieved from https://www.ajol.info/index.php/samj/article/view/50763/39454.

Glanz, K., \& Bishop, D. (2010). The Role of Behavioral Science Theory in Development and Implementation of Public Health Interventions. Public Health Annual Review. https://doi.org/10.1146/annurev.publhealth.012809.103604

Health Information Unit Data on the Performance Review. (2017). Tema General Hospital, 2015-2017, Tema, Greater Accra, Ghana.

Huang, P. L. (2009). A comprehensive definition for metabolic syndrome. Disease models \& mechanisms, 2(5-6), 231-237. https://doi.org/10.1242/dmm.001180

Kaur, J. A. (2014). Comprehensive Review on Metabolic Syndrome. Cardiology Research and Practice, 2014(3). https://doi.org/10.1155/2014/943162

Kodama, S., Tanaka, S., Heianza Y., Fujihara, K., Horikawa, C., Shimano, H., ... \& Sone, H. (2013). Association between Physical Activity and Risk of All-Cause Mortality and Cardiovascular Disease in Patients with Diabetes: A meta-analysis. Diabetes care, 7-34. https://doi.org/10.2337/dc12-0783

Mensah, K. A., \& Asamoah, S. (2016). Factors Influencing Treatment Compliance in Type 2 Diabetes Mellitus Clients at the Komfo Anokye Teaching Hospital Diabetic Clinic, College of Health Sciences, Knustspace. Retrieved from https://myhealthbasics.site/knust-repository

Moore, J. X., Chaudhary, N. \& Akinyemiju, T. (2017). Metabolic Syndrome Prevalence by Race/Ethnicity and Sex in the United States. National Health and Nutrition Examination Survey 1988-2012, 14, 17-24. https://doi.org/10.5888/pcd14.160287

Nancy, T., Gosh, S., \& Hush, F. (2013). Dietary and lifestyle modification factors that affect dietary counseling (5th ed.), Ontario, Canada.

Ofori-Asenso, R., Agyeman, A. A., \& Laar, A. (2017). Metabolic Syndrome in Apparently Healthy Ghanaian Adults: A Systematic Review and Meta-Analysis. International Journal of Chronic Diseases, 3(9). https://doi.org/10.1155/2017/2562374

Okafor C. I. (2012). The Metabolic Syndrome in Africa: Current trends. Indian Journal of Endocrinology and Metabolism, 16(1). https://doi.10.4103/2230-8210.91191

Ranasinghe, P., Mathangasinghe, Y., Jayawardena, R., Priyanga, Y., Hills, A. P., \& Misra, A. (2017). Prevalence and trends of metabolic syndrome among adults in the Asia-pacific region: a systematic review. BMC Public Health, 17, 101. https://doi.org/10.1186/s12889-017-4041-1

Riekert, K. A., Ockene, J. K., \& Pbert, L. (2014). The Handbook of Health Behavior Change (4th ed., pp. 19-45). Retrieved from www.researchgate.net/publication/283074541_The_Handbook_of_Health_Behavior_ Change

Tachang, G. K. (2016). Metabolic Syndrome May be a Sign of Rapid Aging. Journal of Diabetes and Metabolism, 7(5). https://doi.org/10.4172/2155-6156.1000674

Tharman, R. G., \& Arora, G. P. (2013). Metabolic Syndrome: Definition and Pathophysiology. J. Phys. Pharm. 
$A d v$., 3(3). https://doi.org/10.5455/jppa.20130317071355

Toth, P. P., Henriksson, K. M., \& Palmer, M. K. (2016). Metabolic syndrome and low-density lipoprotein cholesterol (LDL-C) goal attainment in the National Health and Nutrition Examination Survey (NHANES)(2003-2012). Anais do NATIONAL LIPID ASSOCIATION SCIENTIFIC SESSIONS, 2(3), 255-356. https://doi.org/10.1016/j.jacl.2016.03.101

Townsend, N., \& Scriven, A. (2014). Common Abnormalities Associated with Intra-Abdominal Fat Accumulation, Public Health Mini-Guides: Obesity. Retrieved from https://b-ok.africa/dl/2337502/5d5900

Tran, S. L., Juliana, S., \& Sakinah, H. (2011). Dietary Compliance and Its Association with Glycemic Control Among Poorly Controlled Type 2 Diabetic Outpatients in Hospital University Saint Malaysia, Malays. J. Nutr. 17(3), 287-299. Retrieved from https://pubmed.ncbi.nlm.nih.gov/29761216.

World Health Organization. (2008). Pathogenesis of metabolic syndrome, media center factsheets. https://doi.org/10.1016/S0151-9638(08)70542-8

World Health Organization. (2010). Global Status Report on Non-communicable Diseases, Geneva, Switzerland, 12(5). Retrieved from https://www.who.int/nmh/publications/ncd_report2010/en.

World Health Organization. (2013). Global Action Plan for the Prevention and Control of Non-Communicable Diseases. Retrieved from https://www.who.int/nmh/publications/ncd-action-plan/en.

Yamaoka, K., \& Tango, T. (2012). Effects of lifestyle modification on the metabolic syndrome: a systematic review and meta-analysis. BMC medicine, 10(1). https://doi.org/10.1186/1741-7015-10-138

\section{Copyrights}

Copyright for this article is retained by the author(s), with first publication rights granted to the journal.

This is an open-access article distributed under the terms and conditions of the Creative Commons Attribution license (http://creativecommons.org/licenses/by/4.0/). 